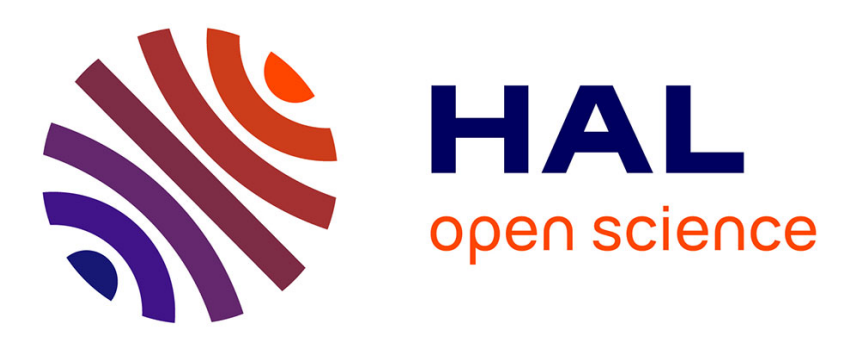

\title{
Phonological priming in auditory word recognition: When both controlled and automatic processes are responsible for the effects.
}

\author{
Sophie Dufour
}

\section{- To cite this version:}

Sophie Dufour. Phonological priming in auditory word recognition: When both controlled and automatic processes are responsible for the effects.. Canadian Journal of Experimental Psychology, 2008, 62 (1), pp.33-41. 10.1037/1196-1961.62.1.33 . hal-01727075

\section{HAL Id: hal-01727075 \\ https://hal.science/hal-01727075}

Submitted on 8 Mar 2018

HAL is a multi-disciplinary open access archive for the deposit and dissemination of scientific research documents, whether they are published or not. The documents may come from teaching and research institutions in France or abroad, or from public or private research centers.
L'archive ouverte pluridisciplinaire HAL, est destinée au dépôt et à la diffusion de documents scientifiques de niveau recherche, publiés ou non, émanant des établissements d'enseignement et de recherche français ou étrangers, des laboratoires publics ou privés. 
Phonological priming in auditory word recognition:

When both controlled and automatic processes are responsible for the effects

\section{Sophie Dufour}

Laboratoire de Psycholinguistique Expérimentale, University of Geneva, Switzerland

Sophie Dufour

Laboratoire de Psycholinguistique Expérimentale FPSE, Université de Genève

40, Bd du Pont d'Arve

CH 1205 Genève

Suisse.

Email: Sophie.Dufour@pse.unige.ch 
Abstract: The phonological priming paradigm provides an interesting methodological tool for studying various components of the speech recognition process. However, concerns about response biases distorting the effects have been repeatedly voiced. Reviewing the main studies on priming, the present paper aims at distinguishing effects under automatic processes from those under some level of strategic control. Both controlled and automatic processes appear to be responsible for the effects observed in phonological priming experiments. Nonetheless, with careful procedures, it is possible to cleave them apart. 
Priming methodologies such as semantic priming and form priming have been used extensively to investigate the structural and processing characteristics of words in memory. In such a paradigm, two words (prime and target) are presented in close temporal succession, and participants perform a task (e.g., lexical decision or shadowing) on the second word. The relationship between the prime and the target is manipulated along semantic or form-based (orthographic / phonological) dimensions. Of interest is what effect the prime has on the processing of the target. In the field of spoken word recognition, one type of form priming that has been of interest is phonological priming.

As I will describe in detail below, effects differ depending on the location of the overlapping segments and on the extent to which primes and targets overlap. For primes that overlap with the final phonemes of targets (e.g. MEAN - BEAN), facilitation of processing has systematically been found (Dumay, Benraïss, Barriol, Colin, Radeau, \& Besson, 2001; Monsell \& Hirsh, 1998; Norris, McQueen, \& Cutler, 2002; Radeau, Besson, Fonteneau, \& Castro, 1998; Radeau, Morais, \& Segui, 1995; Slowiaczek, McQueen, Soltano, \& Lynch, 2000; Spinelli, Segui, \& Radeau, 2001). This effect has been taken to reflect speech recognition processes which occur before lexical access. The effects are more complex when primes overlap in the initial phonemes of targets. When primes overlap with targets in their first one or two phonemes (e.g. DOVE - DREAD), a facilitation effect has sometimes been reported (Goldinger, Luce, Pisoni, \& Marcario, 1992; Hamburger \& Slowiaczek, 1996; Slowiaczek \& Hamburger, 1992). In contrast, when primes overlap with all except the last phoneme of targets (e.g. DRESS-DREAD), an inhibitory effect has been observed (Dufour \& Peereman, 2003a, 2003b; Hamburger \& Slowiaczek, 1996; Monsell \& Hirsh, 1998; Radeau et al., 1995, Slowiaczek \& Hamburger, 1992). The inhibition found when primes and targets 
begin in the same way has been considered to reflect competition between lexical candidates during the recognition process.

The phonological priming paradigm may therefore provide an interesting methodological tool for studying various aspects of the speech recognition system, such as the competition process between activated lexical candidates or the nature of the prelexical and lexical representations that the recognition system relies upon. However, priming effects have not inspired great confidence, and some have argued that the effects originate in response biases that listeners develop in the specific setting of priming experiments, rather than in automatic processes which occur in normal speech recognition. Reviewing the main studies on priming, the present paper aims at distinguishing effects which are automatic from those which are strategic but necessarily linked to human performance (see, Stone \& Van Orden, 1993). If it can be ascertained that the observed phonological priming effects are not due entirely to strategies that listeners develop in response to the experimental task, these studies can inform us about automatic processes that occur whenever listeners deal with their language.

\section{Final overlap}

Final overlap has systematically produced facilitatory effects (i.e., faster responses to LAMP after RAMP than after PINK) independently of the task performed: identification in noise (Slowiaczek, Nusbaum, \& Pisoni, 1987), lexical decision (Monsell \& Hirsh, 1998 ; Norris et al., 2002; Radeau et al., 1995; Radeau, Segui \& Morais, 1994; Slowiaczek et al., 2000; Spinelli et al., 2001) and shadowing (Dumay et al., 2001; Norris et al., 2002; Radeau, 
1995; Radeau et al., 1995; Slowiaczek et al., 2000). The main studies on final overlap priming are summarized in Table 1.

< Insert Table 1 about here >

Studies examining monosyllabic prime-target pairs showed that the effect depends on whether the primes and the targets rhyme (i.e., share all phonemes from the stressed vowel to word offset). In a shadowing task, Radeau (1995) manipulated the amount of overlap between primes and targets. The prime - target pairs shared one (FLEMME - TRAME), two (FLAMME - TRAME) or three (GRAMME - TRAME) phonemes from the end. She observed facilitation for rime overlap (FLAMME - TR $\underline{A M E}$ ) but no increase in the effect when the overlap included the consonant of the onset in addition to the rime (GRAMME T $\underline{\text { RAME}}$. When primes and targets shared only the last consonant (FLEMME - TRAME), no effect was found. In a more recent study using the shadowing task and controlling for the amount of overlap, Slowiaczek et al. (2000) obtained a greater facilitation effect when primes and targets shared the rime $(\underline{\mathrm{RANK}}-\mathrm{BANK})$ than when they did not share it (HONKED BANKED). Slowiaczek et al. also found some evidence for facilitation with monosyllabic prime-target pairs that did not rhyme. This facilitation depends on the number of shared phonemes between the primes and the targets, and was found with an overlap of three (HONKED - BANKED) but not two (HONK - BANK) phonemes.

In studies that have examined bisyllabic prime-target pairs, the amount of facilitation increases with increasing phonological overlap. For example, Dumay et al. (2001) found priming effects when primes and targets shared the complete second syllable (LURAGE TIRAGE) and when they shared only the rime (LUBAGE - TIRAGE), but the facilitation was 
stronger in the former than in the latter condition. No effect was found when the primes and the targets overlapped by only the last consonant (LUSOGE - TIRAGE). Together, these findings suggest that both the rime and the syllable play a specific role in offset phonological priming.

Final overlap facilitation seems to occur rather early in the course of target processing. First, it has been shown to be modality-dependent. The effect is observed only when both the prime and the target are presented auditorily, and dissipates under cross-modal presentation ${ }^{1}$ either when the prime is spoken and the target is visual (Radeau et al., 1994; Spinelli et al., 2001) or the reverse (Dumay et al., 2001). Second, the size of the priming effect does not vary as a function of the relative frequency of prime and target. Similar effects were found for word targets of lower frequency than the primes and for word targets of higher frequency than the primes (Radeau et al., 1995). Finally, final overlap facilitation does not depend on the lexical status of the primes and the targets. Effects were found to be equivalent for word targets preceded by word or nonword primes (Slowiaczek et al., 2000; Spinelli et al., 2001). Also, similar effects were observed for word or nonword targets (Dumay et al., 2001; see also Norris et al., 2002). The observation that final overlap facilitation does not vary as a function of both prime-word frequency and prime and target lexicality clearly suggests that lexical representations are not involved in the effect. Indeed, if this was the case, greater facilitation should have been observed for words than for nonwords, since by definition nonwords have no lexical representations. Moreover, since word frequency necessarily operates at the level of lexical representations, a modulation of the effect as a function of prime-target frequency should have been observed. Hence, final overlap facilitation appears to have a prelexical locus and reflects the repeated activation of prelexical representations (i.e., rime, syllable), that is, the mental representations that mediate the mapping between the acoustic signal and the 
mental lexicon. The processing of the target is thus facilitated because its recognition involves the use of prelexical units that were already activated during prime processing.

Is there a strategic component to final overlap facilitation?

Results from studies examining monosyllabic prime-target pairs indicate that the size of the effect decreases when the ISI (inter-stimulus interval) increases (McQueen \& Sereno, 2005; Radeau et al., 1995). Because it is usually claimed that increasing the ISI provides a better opportunity for the participants to do strategic processing (Radeau et al., 1995), the observation of a smaller effect at longer rather than at shorter ISI appears to argue against a bias contamination. Varying the proportion of related prime - target pairs in a shadowing task, Slowiaczek et al. (2000) found a greater facilitation in the high (75\%) than in the low (26\%) relatedness proportion condition. Because a high proportion of related trials encourages the development of strategies, the effect observed in such a condition could be due in part to controlled processes. A time-ordered analysis on control trials showed that RTs became slower over the course of the experiment in both the high and low proportion related trial conditions. The slowing down on control trials was however not reliable, thus indicating that strategies did not develop over the course of the experiment and that they have no substantial role to play in final overlap facilitation ${ }^{2}$.

Norris et al. (2002) explicitly tested this claim by including foils in a lexical decision task. More specifically, the foils were intended to discourage subjects from developing a bias to say "yes" to targets that rhyme with their primes. On half of the foil trials, nonword targets

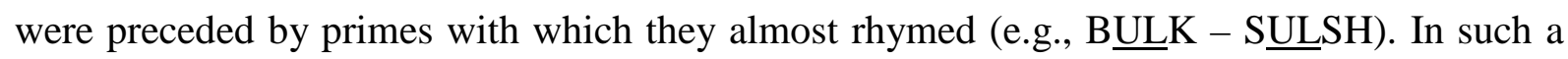
case, anticipation based on a rhyme leads to an incorrect "yes" decision (i.e., the word 
"SULK"). Likewise, on the other half of the foil trials, word targets were preceded by primes with which they almost rhymed (e.g., F $\underline{I L M}$ - KILT). In this case, anticipation based on a rhyme leads to an incorrect "no" decision (i.e., the nonword "KILM"). The authors showed that the facilitation effect was strongly reduced when stimulus lists included foils, thus suggesting that a component of the effect in the lexical decision task is strategic. The effect of the presence of foils was also tested in a shadowing task. Although there was some reduction in the amount of priming when foils were included, the differences were not significant. Moreover, in the shadowing task, the effect was of similar magnitude to that observed for words in the lexical decision task when foils were included. Hence, Norris et al. suggest that there also exists a component of the effect that is nonstrategic and that appears to be due to automatic processing which operates prior to lexical access (see also, Slowiaczek et al. (2000) for the same conclusion).

\section{Initial overlap}

In contrast to final overlap that systematically produces facilitatory priming effects, the priming observed when primes and targets have the same initial part is more complex. As the subsequent review of the literature shows, null, facilitatory and inhibitory effects have been reported depending on the experimental task, the proportion of related prime-target pairs and on the amount of prime-target overlap. The facilitation that is observed in case of an initial overlap has been in large part interpreted as being due to strategic processes. In contrast, the inhibition that has been found when primes and targets begin in the same way has been considered to reflect competition between candidate words during the recognition process. To illustrate the complexity of the effects, the main studies on initial overlap priming are summarized in Table 2 . 
< Insert Table 2 about here>

In a first study using monosyllabic words in a lexical decision task, Slowiaczek and Pisoni (1986) varied the amount of overlap between primes and targets. Although primes facilitated responses to targets in the identity condition (DREAD - DREAD), no priming

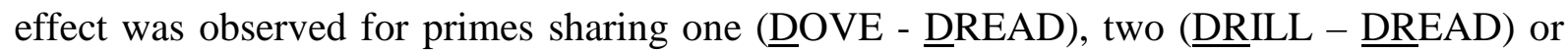
three (DRESS - $\underline{\text { DREAD) }}$ ) phonemes with the targets. However, in a similar experiment using identification in white noise as task, Slowiaczek, Nusbaum and Pisoni (1987) observed a significant facilitation which increased in magnitude with both the number of phonemes shared between the primes and targets, and the degradation of the stimulus. These differences in results were attributed to task differences: The former studies used auditory lexical decision and the latter exploited identification in noise. In particular, Slowiaczek and Pisoni (1986) noted that the lexical decision task involves a small response set, acoustically clear targets, and time pressure. According to the authors, these characteristics of the lexical decision task may dissuade subjects from using phonological information provided by the prime and may make the task insensitive to priming in comparison with the identification task.

On the basis of these results, Radeau, Morais and Dewier (1989) investigated the phonological priming effect further by conducting both lexical decision and shadowing tasks. Except for a repetition priming effect, Radeau et al. reported no evidence for facilitatory priming when the primes and the targets overlapped in their first phonemes (see also Slowiaczek and Pisioni, 1986). In fact, in lexical decision, Radeau et al. observed significant inhibition for target words sharing the first phoneme (POULET - PARURE) or the first

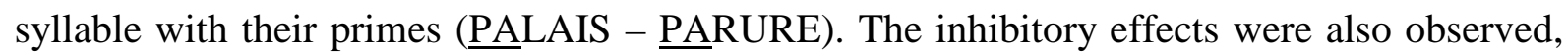
although much reduced, in a shadowing task. However, when repetition trials were excluded, 
no priming effect for word responses was observed in both lexical decision and shadowing tasks. Hence, Radeau et al. concluded that the interference effect was an artefact of the design, that is, a lexical decision task that included identical prime - target pairs. In particular, they proposed that the presence of identical prime-target pairs lead participants to compare the targets to the primes, with repetition trials biasing the decision toward a "yes" response. Phonological relatedness was thus claimed to produce interference effects in lexical decision due to involvement of postlexical strategic checking mechanisms. Moreover, they argued that phonologically related primes do not influence response times to targets and that the facilitation previously observed by Slowiaczek et al. (1987) was due to a guessing strategy. The strategic nature of initial overlap facilitation was subsequently demonstrated by Goldinger and collaborators (Goldinger et al., 1992) who showed that the effect was severely attenuated when the proportion of related prime-target pairs was reduced from $50 \%$ to $10 \%$.

In another study, Slowiaczek and Hamburger (1992) used shadowing in order to minimize the influence of response biases, and in particular post-access processing. They observed that an initial overlap produced two dissociated effects. First, response times (RTs) to auditory target words preceded by primes sharing one (GOALS - GREEN) or two (GROPE - GREEN) phonemes with the targets were faster than RTs to targets preceded by unrelated primes (CLUMP - GREEN). In addition to this "low similarity" facilitation effect, Slowiaczek and Hamburger also found that RTs increased as the phonological overlap between primes and targets increased from one or two phonemes to three phonemes ( $\underline{\text { GRIEF }-~}$ GREEN). In an attempt to determine the locus of these effects, Slowiaczek and Hamburger manipulated both the lexicality (word/nonword) and the modality (auditory/visual) of the primes. They found that the lexical status of the prime influenced the inhibition effect but not the facilitation effect. "High similarity" inhibition was observed only with word primes 
whereas "low similarity" facilitation emerged for both word and nonword primes. On the other hand, prime modality affected the facilitation effect but not the inhibition effect. "Low similarity" facilitation was present only with auditory primes, whereas "high similarity" inhibition was observed with both auditory and visual primes. This pattern of results led Slowiaczek and Hamburger to conclude that "low-similarity" facilitation was a prelexical effect due to phonemic similarity between the primes and the targets. In contrast, "high similarity" inhibition was assumed to reflect competition between the lexical representations of the primes and the targets.

Note that the observation of an inhibitory priming effect has important theoretical implications. In particular, models of spoken word recognition such as Trace (McClelland \& Elman, 1986), Shortlist (Norris, 1994) and NAM (Luce, Pisoni \& Goldinger, 1990), that assume transient competition between similar sounding words in memory, depend crucially on the empirical demonstration of such a competition effect. Studies have thus been devoted to looking for evidence of competitor priming.

Evidence for competition effects in auditory priming experiments was first reported by Goldinger and colleagues (Goldinger, Luce, \& Pisoni, 1989; Goldinger et al., 1992). Somewhat surprisingly, however, the competing prime that produced the strongest evidence for inhibitory priming in their experiments shared no phonemes with the target. In fact, Goldinger et al. (1989) did not examine the effect of priming when primes and targets have phonemes in common. Instead, they examined the effect of priming with prime - target pairs that were phonetically confusable when presented in noise but had no common phonemes (e.g. BULL - VEER). Such a constraint on the materials was imposed to prevent subjects from generating response strategies based on repeated overlap between primes and targets. 
Goldinger et al. (1989) showed that targets were identified less accurately when they were preceded by phonetically similar primes (BULL - VEER) than when they were preceded by phonetically unrelated primes (GUM - VEER). The inhibitory effect was reported when a short ISI (50 ms) was used, and when the primes were low-frequency words. No effect of priming was observed with a longer, $500 \mathrm{~ms}$ ISI, and when the primes were high-frequency words. According to Goldinger et al. (1989), the fact that inhibitory priming effects were restricted to short ISI and low frequency primes is consistent with models assuming transient competition among words in memory. The use of a longer ISI or the faster recognition of high frequency primes eliminated the competition before target presentation. As a consequence, target recognition was unaffected by the priming manipulation.

Having identified an inhibitory priming effect free of response biases, Goldinger et al. (1992) juxtaposed in a subsequent study, the phonetic and the phonological priming tasks. The inhibitory priming effect reported by Goldinger et al. (1989) for phonetic overlap was replicated in both the identification in noise and the lexical decision task regardless of the proportion of related trials used in the experiment. In lexical decision, Goldinger et al. (1992) also found evidence for an inhibitory priming effect with monosyllabic prime-target pairs overlapping on the first phoneme ( $\underline{R} A M-\underline{R} U N)$. This effect occurred with $10 \%$ of related prime-target pairs and $50 \mathrm{~ms}$ ISI. Just as the inhibition found in the context of phonetic priming, the inhibition observed in the context of phonological priming disappeared when the ISI was increased from 50 to $500 \mathrm{~ms}$. Hence, the observation that initial overlap inhibition does not occur when more time is given to participants (with a long ISI) argues in favour of an automatic component for the effect, reflecting transient competition between lexical candidates. 
Compatible with the claim that phonemic overlap inhibition reflects automatic competition between the lexical representation of the primes and targets, Radeau et al. (1995) have shown that the effect varies as a function of the relative frequency of primes and targets. In particular, they reported an inhibitory priming effect in a shadowing task, only when the primes were of lower frequency than the targets. No effect was found when the primes were of higher frequency than the targets. Also, Dufour and Peereman (2003a) recently reported an inhibitory priming effect for words which come from sparse neighborhoods but not for words which come from dense neighborhoods. According to Dufour and Peereman, the inhibitory effect is stronger for words with few neighbors than for words with many neighbors, because the reactivated prime competes more effectively with the target when there are fewer other words in the competition process. Hence, the observation that both the neighborhood density of the target words and the relative prime-target frequency influence the size of the inhibitory priming effect strongly suggests that the effect reflects lexical processing, and in particular competition between lexical candidates.

The inhibitory effect observed for phonetic priming and that for phonological priming are potentially contradictory. The contradiction is introduced because both effects have been interpreted in terms of competition between the lexical representations of the primes and the targets. Nonetheless, in one case, competition depends on the number of shared phonemes between primes and targets (Slowiaczek \& Hamburger, 1992; see also, Dufour \& Peereman, 2003b) and in the other case, competition occurs when primes and targets share no phonemes. A possibility to account for these two types of inhibitory priming is to envisage an interactive - activation model that entails phoneme and word level inhibition, as was the case in the TRACE model (McClelland \& Elman, 1986) ${ }^{3}$. This model assumes separate levels of representation for features, phonemes and words. Each level sends excitatory activation to 
each other, and within each level there are inhibitory connections between nodes. Imagine a case in which the target word ROPE is preceded by either the prime LOB (phonetic priming) or the prime ROB (phonological priming). During the processing of the prime, the similarity between the phonemes of the prime /LOB/ and those of the target /ROPE/ in the context of phonetic priming would lead to the inhibition of the nodes corresponding to each phoneme of the target. For example, because the phonemes $/ 1 /$ and $/ \mathrm{r} /$ share phonetic features, the $/ \mathrm{r} /$ phoneme should receive activation from the feature level during the processing of the prime LOB. The $/ 1 /$ and $/ \mathrm{r} /$ phonemes being activated, they should naturally compete via intra-level inhibition during processing. To win the competition, the /l/ phoneme of the prime /LOB/ must suppress the phoneme competitor /r/. The phonemes of the target /ROPE/ being inhibited for a brief period, the subsequent processing of the target is delayed, leading thus to the inhibitory phonetic priming effect reported by Goldinger (Goldinger et al., 1989; Goldinger et al., 1992; Goldinger, 1998; Luce, Goldinger, Auer \& Vitevitch, 2000). In the phonological priming case, the great similarity between the prime and the target would lead to a strong activation of the target word /ROPE/ during processing of the prime /ROB/. Both the prime and the target being highly activated, they should compete for recognition via intraword inhibition. To be recognized the prime ROB must necessarily suppress its competitors, such as the target ROPE. The target word ROPE being inhibited, its subsequent processing is delayed, thereby causing an inhibitory phonological priming effect.

What are the relative contributions of strategic and automatic processes in initial overlap effects?

It is clear from the studies discussed above, that an important part of the initial overlap facilitation effect when primes and targets share one or two phonemes is due to strategic 
processes (Goldinger et al., 1992; Radeau et al., 1989). Although a consensus has been reached concerning the strategic nature of the facilitation effect, there is disagreement regarding the implication of response biases in initial overlap inhibition. Nonetheless, as we will see, all studies converge in showing that strategic effects mask, but in no case cause initial overlap inhibition. Below, I review the data and the conclusions of studies that directly tested for the role of strategic processes and which are thus at the heart of the debate regarding the automatic component of the initial overlap priming effects.

The strategic nature of the facilitatory priming effect in case of a one-phoneme overlap between primes and targets has been clearly demonstrated in a study by Goldinger (1998). Goldinger (1998) again compared phonetic and phonological priming, using signal detection methods in a forced-choice task with clear spoken primes and degraded targets. The critical manipulation concerned block order. Half the subjects received a phonetic priming block (e.g. LOB - ROPE; response option: ROPE or LOPE, LOPE being phonologically related to the prime LOB) followed by a phonological priming block (e.g. ROB - ROPE; response option: ROPE or LOPE, LOPE being phonetically related to the prime ROB). The other half received these blocks in reverse order. Goldinger (1998) hypothesized that if subjects develop a strategy in the phonological block, performance in the phonetic block should be systematically altered when it follows a phonological block. In particular, a bias to respond "yes" when the word shares the prime's initial phoneme would reduce hits and increase false alarms (FA) in the subsequent phonetic priming. Overall, phonetic priming was again inhibitory and phonological priming facilitatory. As expected, phonetic priming yielded lower hit rates and more FAs when subjects had already completed a phonological block. Together, the data indicate that in the context of phonological priming, subjects rapidly learn that targets sometimes share their initial phoneme with the primes and thus develop a response bias in 
favour of phonologically related words that carries over to a later phonetic priming context. In contrast to phonological priming, phonetic priming has proven to be relatively immune to response biases, probably due to the subtle relation between prime-target pairs. Note however, that phonological priming was examined in a narrow sense. Only prime-target pairs sharing one initial phoneme were tested. Thus, such a study provides no information regarding the nature (strategic/automatic) of the inhibition found by Slowiaczek and Hamburger (1992) in the three-phoneme overlap condition.

In an attempt to distinguish strategic effects from automatic effects, Hamburger and Slowiaczek (1996) examined phonological priming effects in a shadowing task under conditions that either promote strategic processing (with $75 \%$ related prime-target pairs and $500 \mathrm{~ms}$ ISI) or discourage strategic processing (with $21 \%$ related trials and $50 \mathrm{~ms}$ ISI). Recall that strategic anticipations are not expected to occur with $25 \%$ related prime-target pairs, because an assumption by participants that the targets are likely to begin with the same segments as their primes tends to impair performance on most of the trials. Their earlier data were replicated with a high proportion of related trials (75\%) and a long ISI (500 ms) showing facilitation with a one- or a two- phoneme overlap and inhibition with a three-phoneme overlap. However, the facilitation effect vanished with a low proportion of related trials $(21 \%)$ and a short ISI (50 ms), while the magnitude of the inhibition effect increased. Because the facilitation priming effect was larger under conditions that make it easier for participants to develop strategic anticipations (with $75 \%$ related trials), Hamburger and Slowiaczek also concluded that response biases are responsible for the facilitation effect. In the case of a high proportion of related trials, participants would notice that the targets are likely to begin with the same segments as the primes and they would anticipate the first phonemes of the targets, thus achieving faster responses on targets preceded by related primes. In contrast, because the 
inhibition effect is stronger when strategic biases are minimized, Hamburger and Slowiaczek assumed that it results from automatic processes involving competition between the lexical representations of the primes and the targets.

Goldinger (1999) has however reported, that the use of a low proportion of related prime-target pairs does not guarantee the abscence of strategic processes. In a replication of Hamburger and Slowiaczek (1996)'s study, Goldinger (1999) attempted to provide evidence for response biases by examining how performance on control trials developed over the course of the experiment. He reasoned that if participants develop strategic processes intended to maximize performance on related trials, a cost on control trials should be systematically observed. This was in fact what Goldinger found. Relative to a pure control condition with no related trials, RTs on target words preceded by unrelated primes became slower as the experiment progressed for both the high and the low proportion of related prime - target pair conditions. The slowdown on control trials was weaker when a low proportion of related pairs was used, but both high and low relatedness proportion control conditions produced slower overall performance than the pure control condition. Such observations thus suggest that even in a condition intended to minimize strategic influences, response biases cannot completely be removed. Hence, Goldinger argued that the inhibition observed when primes and targets shared three phonemes is the result of an "inefficient" bias. According to Goldinger, inhibitory priming effects occur because participants "avoid anticipating more prime phonemes than targets truly contain". Although in a reanalysis of Hamburger and Slowiaczek (1996)'s data, Hamburger and Slowiaczek (1999) also showed that biases were reduced but not eliminated by the use of a low proportion of related trials, they maintain that the three phoneme overlap inhibition is the result of an automatic competition between the lexical representations of the primes and the targets. This is because the inhibition is stronger when 
strategic biases are weaker, thus making it unlikely that response biases cause inhibitory priming effects ${ }^{4}$. Hence, while it seems impossible to remove all response biases under lowexpectancy conditions, at least part of the inhibition effect is probably not due to biases.

The debate does not end here, however. Whereas Goldinger (1999) focused only on the RT cost in the control condition, Pitt and Shoaf (2002) collected data on both related and unrelated prime-target pairs at different points during the experiment. They reasoned that if the inhibitory priming effect is evidence for lexical competition, the effect should be of similar magnitude at the beginning and end of the experiment. As in Slowiaczek and Hamburger (1992) and Hamburger and Slowiaczek (1996), primes and targets shared zero

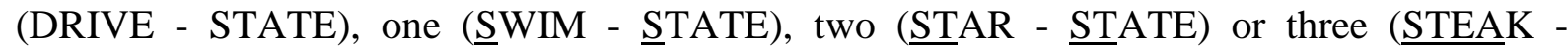

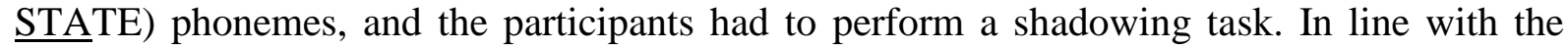
study of Hamburger and Slowiaczek (1996), the ISI and the proportion of related prime-target pairs were manipulated. Overall, the results of Slowiaczek and Hamburger (1992) and Hamburger and Slowiaczek (1996) were closely replicated. The facilitation effect observed with a one- or two- phoneme overlap under conditions including a high proportion of related trials $(70-80 \%)$ and a long ISI $(500 \mathrm{~ms})$ vanished when the proportion of related trials decreased $(10 \%)$ and the ISI was shortened $(50 \mathrm{~ms})$. In contrast, prime-target pairs having a three-phoneme overlap produced a reliable inhibition effect only with a low proportion of related trials $(10 \%)$ and a short ISI (50 ms). Critically, however, a close examination of the data revealed that the size of inhibitory priming effect decreased between the beginning and the end of the experiment. A strong inhibitory priming effect occurred at the onset of the experiment, but no inhibition was observed at the end of the experiment even with a low proportion of related trials and a short ISI. To account for these data, Pitt and Shoaf (2002) claimed that inhibitory priming effects are due to participants' surprise when they encounter 
the first related trial. Moreover, they suggest that priming effects are distorted by strategic anticipations that participants develop in order to maximize fast responses on related trials, once the phoneme overlap between primes and targets is noticed. The surprise account for the inhibitory priming effect is however difficult to reconcile with experimental findings available in the literature that showed that the effect occurred when the participants were assumed to know via the training session, that the primes and targets sometimes overlapped in their first phonemes (Dufour \& Peereman, 2003a, 2003b).

As initially suggested by Goldinger (1999), McQueen and Sereno (2005) recently attempted to induce an expectancy-based strategy, and then tested for effects of initial overlap both when the expectations of the learned strategy were met, and on occasional unexpected trials. To this end, Dutch participants learned to expect that, after a particular prime, if the target was a word, it would have a particular phonological form. For example, they learned that after the prime "KNAK ", the target word is "KNAP". The expectancy either involved phonological overlap (KNAK \KNAP) or did not (TROG \SLIM). Critical trials were those for which targets were inconsistent with expectations. For example, after the prime "TROG", for which participants expected an unrelated word, the target was a related word (TROTS). Also, after the prime "KNAK", for which participants expected a related word, the target was unrelated (TROS). The amount of initial overlap which was either one or three phonemes, and the ISI which was either 50,500 or $2,000 \mathrm{~ms}$, were manipulated. For the one- onset phoneme overlap condition, the lexical decision task results showed no effect of phonological relatedness at all ISIs, that is, responses were not faster to targets which shared the first phoneme with their primes than to targets which were phonologically unrelated to their primes. Compatible with previous observations (Hamburger and Slowiaczek, 1996), this finding indicates that a single onset phoneme overlap is not sufficient for automatic 
facilitation of processing to be observed. For the multiple onset phoneme overlap condition, the authors reported a relatedness effect with faster responses for target words preceded by a related prime than for target words preceded by an unrelated prime ${ }^{5}$. The relatedness effect was stronger at shorter ISIs (50 and $500 \mathrm{~ms}$ ), thus indicating that the processing benefit due to phonological overlap decays over time. They also observed an expectancy effect with RTs being faster for expected than for unexpected target words, thus indicating that listeners were able to make use of phonological expectancies to bias their lexical decisions in favour of expected targets. In contrast to the relatedness effect, the expectancy effect became stronger as the ISI increased. Together, these observations indicate that there is an automatic component in three-phoneme onset priming in spite of a strategic expectancy bias that becomes increasingly effective with increasing ISI.

\section{$\underline{\text { Conclusion }}$}

The present historical survey of the phonological priming literature illustrates the complexity of the effects and the controversies with respect to the distinction between automatic and strategic processes. Because the effects observed are greatly dependent on the position of the overlapping segments, I have examined separately final and initial overlap effects. In addition to the location of the overlap, the amount of overlap is another variable that has been frequently manipulated.

With respect to final overlap, robust facilitatory priming effects have been observed. They appear to depend heavily on whether the primes and the targets rhyme (Radeau, 1995; Slowiaczek et al., 2000). The observation that final overlap facilitation does not vary as a function of lexical factors such as the lexicality of the primes and the targets (Dumay et al., 
2001; Norris et al., 2002; Slowiaczek et al., 2000; Spinelli et al., 2001) or the prime-target relative frequency (Radeau et al., 1995) suggests that the effect occurs rather early — before lexical access — in the course of the processing of the target. Most authors have therefore assumed that rhyme-based facilitation reflects the repeated activation of prelexical representations (Dumay et al., 2001; Norris et al., 2002; Radeau et al., 1995; Slowiaczek et al., 2000; Spinelli et al., 2001). Compatible with this view, studies that have varied the ISI (McQueen \& Sereno, 2005; Radeau et al., 1995) indicate that the effect becomes weaker over time, as the activation of prelexical representations caused by the primes returns to resting levels. It appears however, that the presence of foils strongly reduces the amount of priming in a lexical decision task (Norris et al., 2002). This observation suggests that part of the effect is strategic. Nonetheless, in a shadowing task, Norris et al.'s study showed that the foil manipulation did not significantly reduce the amount of priming. Moreover, the effect observed in a shadowing task was of similar magnitude to that observed in a lexical decision task when strategic biases were discouraged by the inclusion of foils. Thus, it seems that the effect observed in a shadowing task is due to automatic prelexical processes. In line with this suggestion, Slowiaczek et al. (2000) reported no evidence of response biases through a timeordered analysis when the shadowing task was used. Hence, it appears that clear automatic effects can be observed at least in a shadowing task when primes overlap with the final phonemes of targets.

The effects observed when the primes and the targets begin in the same way depend on the amount of overlap. A facilitatory priming effect has been reported when the primes and the targets overlap in a small number of phonemes (i.e., one or two phonemes, Goldinger et al., 1992; Hamburger \& Slowiaczek, 1996; Slowiaczek \& Hamburger, 1992). In contrast, with a small deviation between the primes and the targets, an inhibitory priming effect has been 
reported (Dufour \& Peereman, 2003a, 2003b; Hamburger \& Slowiaczek, 1996; Monsell \& Hirsh, 1998; Radeau et al., 1995, Slowiaczek \& Hamburger, 1992). In fact, Dufour and Peereman (2003b) showed that inhibitory priming occurs provided that the primes mismatch the targets only on the last phoneme (e.g., BAGARRE - BAGAGE). Note however, that McQueen and Sereno (2005) recently reported a facilitatory priming effect with multiple onset overlap. As discussed by the authors, one reason that they have failed to observe an inhibitory priming effect may be related to the neighborhood density of the target - words. The words used by McQueen and Sereno came from dense neighborhoods. In line with this idea, Dufour and Peereman (2003a) recently reported a significant inhibitory priming effect for words with few neighbors but no inhibition emerged for words with many neighbors. Hence, the neighborhood density of the targets could be responsible for this difference in the effect of multiple onset overlap.

It is clear from the studies summarized above, that the facilitatory effect observed with a small overlap between the primes and the targets is strategically induced. The effect depends on high relatedness proportion (Goldinger et al., 1992; Hamburger \& Slowiaczek, 1996). Under such a condition, participants seem to learn that targets often begin in the same way as the preceding primes and they anticipate the first phonemes of the targets, thus achieving faster responses on targets preceded by related primes. Controversy remains however about the nature (automatic/strategic) of the multiple onset overlap effect. The facilitatory effect recently reported by McQueen and Sereno (2005) appears to have both automatic and strategic components. The claim that automatic processes mediate multiple onset overlap facilitation was mainly motivated by the observation of a priming effect on unexpected related target words. With respect to the inhibitory effect found with multiple onset overlap, some authors (Goldinger, 1999; Pitt \& Shoaf, 2002) have argued that it reflects response biases 
rather than automatic processes occurring in normal speech recognition. Such a claim relies on the observations that RTs on control trials become slower over the course of the experiment (Goldinger, 1999) and that the effect only occurs at the beginning of the experiment (Pitt \& Shoaf, 2002).

There is however strong evidence suggesting that response biases alone cannot be responsible for the inhibitory priming effect. First, Hamburger and Slowiaczek (1996) found that inhibitory priming is stronger under conditions that reduce the likelihood of strategic processes (with 25\% related prime-target pairs). Such an observation suggests that response biases mask but in no case cause inhibitory priming effects. The same conclusion can be drawn from the study of Pitt \& Shoaf (2002) that shows that the size of the inhibitory priming effect decreases as strategic processes build up. Second, it was shown that the inhibitory priming effect varies as a function of lexical factors such as the lexicality of the prime (Slowiaczek \& Hamburger, 1992), the prime-target relative frequency (Radeau et al., 1995) or the neighborhood density of target words (Dufour \& Peereman, 2003a). At first sight, there is no reason to believe that the size of an effect resulting from response biases should vary as a function of lexical factors. Hence, it seems that an important part of the effect is lexical in nature and results from automatic competition between the lexical representations of the primes and the targets.

To summarize, both automatic and controlled processes appear to be responsible for the effects observed in phonological priming experiments. The relative contributions of strategic and automatic components appear to vary as a function of the experimental task and the proportion of related prime-target pairs. Nonetheless, with careful data analysis and experimentation such as time - ordered analyses (Goldinger, 1999, Hamburger \& Slowiaczek, 
1999; Slowiaczek et al., 2000), manipulations of probe - position (Pitt \& Shoaf, 2002), presence of foils (Norris et al., 2002) or expectancy manipulations (McQueen \& Sereno, 2005), it is possible to separate automatic processes from strategic biases. Hence, the phonological priming paradigm appears to be a useful tool for studying various components of the speech recognition process. 


\section{References}

Dufour, S., \& Peereman, R. (2003a). Inhibitory priming effects in auditory word recognition: When the target's competitors conflict with the prime word. Cognition, $\underline{88}$, B33-B44.

Dufour, S., \& Peereman, R. (2003b). Lexical Competition in phonological priming: Assessing the role of phonological match and mismatch lengths between primes and targets. Memory and Cognition, 31, 1271-1283.

Dumay, N., Benraïss, A., Barriol, B., Colin, C., Radeau, M., \& Besson, M. (2001). Behavioral and electrophysiological study of phonological priming between bisyllabic spoken words. Journal of Cognitive Neuroscience, $13,121-143$.

Goldinger, S.D. (1998). Signal detection comparisons of phonemic and phonetic priming: The flexible-bias problem. Perception \& Psychophysics, $\underline{60}$, 952-965.

Goldinger, S. D. (1999). Only the Shadower knows: Comment on Hamburger \& Slowiaczek (1996). Psychonomic Bulletin and Review, 6, 347-351.

Goldinger, S. D., Luce, P. A., \& Pisoni, D. B. (1989). Priming lexical neighbors of spoken words: Effects of competition and inhibition. Journal of memory and language, $\underline{28}, 501$ 518.

Goldinger, S. D., Luce, P. A., Pisoni, D. B., \& Marcario, J.K. (1992). Form-based priming in spoken word recognition: The roles of competition and bias. Journal of Experimental Psychology: Learning, Memory and Cognition, 18, 1211-1238.

Hamburger, M. B., \& Slowiaczek, L. M. (1996). Phonological priming reflects lexical competition. Psychonomic Bulletin \& Review, $\underline{3}$, 520-525.

Hamburger, M. B., \& Slowiaczek, L. M. (1999). On the role of bias in dissociated phonological priming effects: A reply to Goldinger (1999). Psychonomic Bulletin \& Review, $\underline{6}, 352-355$. 
Luce, P.A., Goldinger, S.D., Auer E.T. Jr., \& Vitevitch, M. S. (2000). Phonetic priming, neighborhood activation and PARSYN, Perception \& Psychophysics, $\underline{62}, 615-625$.

Luce P. A., Pisoni D. B., Goldinger S. D. (1990). Similarity neighborhoods of spoken words. in G. T. M. Altmann (Ed.), Cognitive models of speech processing: Psycholinguistic and computational perspectives (pp. 122-147). Cambridge, MA: MIT Press.

McClelland, J.L. \& Elman J.L. (1986). The TRACE model of speech perception, $\underline{\text { Cognitive }}$ $\underline{\text { Psychology, }} \underline{18}, 1-86$.

McQueen, J. M. \& Sereno, J. (2005). Cleaving automatic processes from strategic biases in phonological priming. Memory and Cognition, 33,1185 - 1209.

Monsell, S., \& Hirsh, K.W. (1998). Competitor priming in spoken word recognition. Journal of Experimental Psychology: Learning, Memory \& Cognition, 24, 1495-1520.

Norris, D. (1994). SHORTLIST: a connectionist model of continuous speech recognition. Cognition, 52, 189-234.

Norris, D., McQueen, J.M, \& Cutler, A. (2002). Bias effects in facilitatory phonological priming. Memory and Cognition, $\underline{30}$, 399-411.

Pitt, M.A. \& Shoaf, L. (2002). Revisiting bias effects in word-initial phonological priming. Journal of Experimental Psychology: Human Perception and Performance, 28, 11201130.

Radeau, M. (1995). Facilitatory and inhibitory phonological priming effects as a function of overlap position. Abstracts of the $36^{\text {th }}$ Annual Meeting of the Psychonomic Society, PP. 59, Los Angeles, CA. 
Radeau, M., Besson, M., Fonteneau, E., \& Castro, S.L. (1998). Semantic, repetition, and rime priming between spoken words: Behavioral and electrophysiological evidence. Biological Psychology, 48, 183-204.

Radeau, M., Morais, J., \& Dewier, A. (1989). Phonological priming in spoken word recognition: Task effects. Memory and Cognition, $\underline{17}, 525-535$

Radeau, M., Morais, J., \& Segui, J. (1995). Phonological priming between monosyllabic spoken words. Journal of Experimental Psychology: Human Perception and Performance, $\underline{21}, 1297-1311$.

Radeau, M., Segui, J. \& Morais, J. (1994). The effect of overlap position in phonological priming between spoken words. Proceedings of the International Conference on Spoken Language Processing, pp. 1419-1422, yokohama, Japan.

Ratcliff, R., Allbritton, D., \& McKoon, G. (1997). Bias in auditory priming. Journal of Experimental Psychology: Learning, Memory, and Cognition, 23, 143-152.

Seron, X., \& Jeannerod, M. (1994). Neuropsychologie Humaine. Mardaga, Liège, Belgium.

Slowiaczek, L. M., \& Hamburger, M. B. (1992). Prelexical facilitation and lexical interference in auditory word recognition. Journal of Experimental Psychology: Learning, Memory and Cognition, $18,1239-1250$.

Slowiaczek, L.M., McQueen, J., Soltano, E.G., \& Lynch, M. (2000). Phonological representations in prelexical speech processing: Evidence from form-based priming. Journal of Memory and Language, $\underline{43}, 530-560$.

Slowiaczek, L. M., Nusbaum, H. C., \& Pisoni, D. B. (1987). Phonlogical priming in auditory word recognition. Journal of Experimental Psychology: Learning, Memory and Cognition, $\underline{13}$, 64-75. 
Slowiaczek, L. M., \& Pisoni, D. B. (1986). Effects of phonological similarity on priming in auditory lexical decision. Memory and Cognition, 14, 230-237.

Spinelli, E., Segui, J., \& Radeau, M. (2001). Phonological priming in spoken word recognition with bisyllabic targets. Language and Cognitive Processes, $\underline{16}$, 367-392.

Stone, G. O., \& Van Orden, G. C. (1993). Strategic control of processing in visual word recognition. Journal of Experimental Psychology: Human Perception and Performance, $\underline{19}, 744-774$. 


\section{Footnotes}

1: The logic underlying cross-modal presentation is that a priming effect with a prelexical locus should not be observed when primes and targets are presented in different modalities. In contrast, an effect with a lexical locus should be modality independent and should be of similar magnitude when tested in different modalities. Such arguments are based on neuropsychological evidence suggesting that written and spoken words are processed by separate and modality-specific input lexicons (see Seron \& Jeannerod, 1994, for a review). These lexicons receive inputs from the auditory and the visual analysis systems, and are assumed to contain only phonological and orthographical representations, respectively. The word meanings are stored in a common higher level supramodal system.

2: If participants develop strategic anticipations in order to maximize fast responses on related trials, a cost on control trials should be observed (see Goldinger, 1999). Unfortunately, Slowiaczek et al. did not report the statistical power needed to detect a difference among the means. Hence, it remains possible that the lack of significance is simply related to a lack of power, especially in the high relatedness proportion condition in which strategies are more likely to develop. Nonetheless, as Slowiaczeck et al. suggested, the facilitation observed under a low relatedness proportion condition is probably in large part not due to an expectancy-based strategy. Indeed, such a condition makes it unlikely that participants would use information provided by the primes to anticipate the target words, since an assumption by participants that the targets will be related with their primes would tend to impair performance on most of the trials. 
3: I thank Stephen Goldinger for this suggestion.

4: Given initial overlap, another possibility to account for inhibitory priming effects is that participants strategically reactivate the prime while the target unfolds, thus creating interference (see Ratcliff, Allbritton, \& McKoon, 1997; see also, Luce et al., 2000). It is unclear however how such a strategy could account for the observation of a smaller inhibitory priming effect in the high relatedness proportion condition in which the targets begin with the same phonemes as their primes in three-quarters of the trials.

5: Curiously, McQueen and Sereno (2005) reported a facilitatory priming effect with multiple onset phoneme overlap. Such a result is incompatible with Hamburger and Slowiaczek (1996)'s observation of an inhibitory priming effect with a large overlap between primes and targets. This point will be discussed in conclusion. 


\section{Acknowledgements}

I thank Stephen Goldinger, Jennifer Stolz and Bruce Milliken who provided helpful comments on earlier version of this manuscript. Thanks to Ronald Peereman for numerous discussions on phonological priming. Many thanks also to Uli Frauenfelder for his advice on a previous draft of the manuscript. 
Table 1: Summary of the main studies on final overlap priming. Only the effects obtained under unimodal presentation are reported.

\begin{tabular}{|c|c|c|c|c|c|}
\hline Study & Task & PRP & ISI & Overlap & Effect \\
\hline Slowiaczek et al. (1987) & $\begin{array}{l}\text { Identification } \\
\text { Identification }\end{array}$ & $\begin{array}{l}80 \\
80\end{array}$ & $\begin{array}{l}500 \\
500\end{array}$ & $\begin{array}{l}\text { coda } \\
\text { rime }\end{array}$ & $\begin{array}{l}\text { No Effect } \\
\text { Facilitation }\end{array}$ \\
\hline Radeau et al. (1995) & $\begin{array}{l}\text { LDT } \\
\text { LDT } \\
\text { Shadowing } \\
\text { Shadowing }\end{array}$ & $\begin{array}{l}17 \\
17 \\
17 \\
17\end{array}$ & $\begin{array}{l}20 \\
500 \\
20 \\
500\end{array}$ & $\begin{array}{l}\text { rime } \\
\text { rime } \\
\text { rime } \\
\text { rime }\end{array}$ & $\begin{array}{l}\text { Facilitation } \\
\text { Facilitation } \\
\text { Facilitation } \\
\text { Facilitation }\end{array}$ \\
\hline Monsell \& Hirsh (1998) & LDT & 50 & $1-5 \min$ & rime & Facilitation \\
\hline Slowiaczek et al. (2000) & $\begin{array}{l}\text { Shadowing } \\
\text { Shadowing } \\
\text { Shadowing } \\
\text { Shadowing } \\
\text { LDT }^{2} \\
\text { LDT }^{2}\end{array}$ & $\begin{array}{c}20-26 \\
20-26 \\
20-26 \\
25 \\
15 \\
15\end{array}$ & $\begin{array}{c}50 \\
50 \\
50 \\
50\end{array}$ & $\begin{array}{l}\text { rime } \\
\text { 2ph (no-rime) } \\
3 \mathrm{ph} \text { (no-rime) } \\
\text { vowel } \\
\text { rime } \\
\text { vowel }\end{array}$ & $\begin{array}{l}\text { Facilitation } \\
\text { No effect } \\
\text { Facilitation } \\
\text { No effect } \\
\text { Facilitation } \\
\text { No effect }\end{array}$ \\
\hline Dumay et al. (2001) & $\begin{array}{l}\text { Shadowing } \\
\text { Shadowing } \\
\text { Shadowing }\end{array}$ & $\begin{array}{l}24 \\
24 \\
24\end{array}$ & $\begin{array}{l}20 \\
20 \\
20\end{array}$ & $\begin{array}{l}\text { coda }^{1} \\
\text { rime } \\
\text { syllable }\end{array}$ & $\begin{array}{l}\text { No Effect } \\
\text { Facilitation } \\
\text { Facilitation }\end{array}$ \\
\hline Spinelli et al. (2001) & LDT & 25 & 50 & syllable & Facilitation \\
\hline Norris et al. (2002) & $\begin{array}{l}\text { LDT } \\
\text { Shadowing }\end{array}$ & $\begin{array}{l}25 \\
25\end{array}$ & $\begin{array}{l}50 \\
50\end{array}$ & $\begin{array}{l}\text { rime } \\
\text { rime }\end{array}$ & $\begin{array}{l}\text { Facilitation } \\
\text { Facilitation }\end{array}$ \\
\hline McQueen \& Sereno (2005) & $\begin{array}{l}\text { LDT } \\
\text { LDT }\end{array}$ & $\begin{array}{l}70 \\
70\end{array}$ & $\begin{array}{l}50 \\
500,2,000\end{array}$ & $\begin{array}{c}\text { rime } \\
\text { rime }\end{array}$ & $\begin{array}{l}\text { Facilitation } \\
\text { No effect }\end{array}$ \\
\hline
\end{tabular}

Note: PRP, proportion of related trials (in \%); ISI, inter-stimulus interval (in ms, except for the Monsell \& hirsh (1998) study); ph, number of phonemes; LDT, lexical decision task

1: The final consonant

${ }^{2:}$ In a continuous lexical decision with no intervening items between the primes and the targets 
Table 2: Summary of the main studies on initial overlap priming

\begin{tabular}{|c|c|c|c|c|c|}
\hline Study & Task & PRP & ISI & Overlap & Effect \\
\hline Slowiaczek \& Pisoni (1986) ${ }^{1}$ & LDT & 75 & 50 & $1,2,3$ & No effect \\
\hline Slowiaczek et al. (1987) & Identification & 80 & 500 & $1,2,3$ & Facilitation \\
\hline Radeau et al. (1989) ${ }^{2}$ & $\begin{array}{l}\text { LDT } \\
\text { Shadowing }\end{array}$ & $\begin{array}{l}50 \\
50\end{array}$ & $\begin{array}{l}\mathrm{SOA}=850 \\
\mathrm{SOA}=850\end{array}$ & $\begin{array}{l}1,2,3 \\
1,2,3\end{array}$ & $\begin{array}{l}\text { No effect } \\
\text { No effect }\end{array}$ \\
\hline Radeau et al. (1995) & $\begin{array}{l}\text { LDT } \\
\text { Shadowing } \\
\text { Shadowing }\end{array}$ & $\begin{array}{l}17 \\
17 \\
17\end{array}$ & $\begin{array}{l}20,500 \\
20 \\
500\end{array}$ & $\begin{array}{l}2 \\
2 \\
2\end{array}$ & $\begin{array}{l}\text { No effect } \\
\text { Inhibition } \\
\text { No effect }\end{array}$ \\
\hline Goldinger et al. (1992) & $\begin{array}{l}\text { Identification } \\
\text { LDT } \\
\text { LDT } \\
\text { LDT }\end{array}$ & $\begin{array}{l}10,50 \\
50 \\
10 \\
10\end{array}$ & $\begin{array}{l}50 \\
50,500 \\
50 \\
500\end{array}$ & $\begin{array}{l}1 \\
1 \\
1 \\
1\end{array}$ & $\begin{array}{l}\text { Facilitation } \\
\text { Facilitation } \\
\text { Inhibition } \\
\text { No effect }\end{array}$ \\
\hline Monsell \& Hirsh (1998) & LDT & 50 & $1-5 \min$ & $2,3,4$ & Inhibition \\
\hline Slowiaczek \& Hamburger (1992) & $\begin{array}{l}\text { Shadowing } \\
\text { Shadowing }\end{array}$ & $\begin{array}{l}75 \\
75\end{array}$ & $\begin{array}{l}500 \\
500\end{array}$ & $\begin{array}{l}1,2 \\
3\end{array}$ & $\begin{array}{l}\text { Facilitation } \\
\text { Inhibition }\end{array}$ \\
\hline Hamburger \& Slowiaczek (1996) & $\begin{array}{l}\text { Shadowing } \\
\text { Shadowing } \\
\text { Shadowing } \\
\text { Shadowing }\end{array}$ & $\begin{array}{l}75 \\
75 \\
21 \\
21\end{array}$ & $\begin{array}{c}500 \\
500 \\
50 \\
50\end{array}$ & $\begin{array}{l}1,2 \\
3 \\
1,2 \\
3\end{array}$ & $\begin{array}{l}\text { Facilitation } \\
\text { Inhibition } \\
\text { No effect } \\
\text { Inhibition }\end{array}$ \\
\hline Dufour \& Peereman (2003b) & Shadowing & 25 & 50 & $2,3,4$ & Inhibition \\
\hline McQueen \& Sereno (2005) & $\begin{array}{l}\text { LDT } \\
\text { LDT } \\
\text { LDT }\end{array}$ & $\begin{array}{l}30 \\
70 \\
70\end{array}$ & $\begin{array}{l}50,500,2000 \\
50,500 \\
2000\end{array}$ & $\begin{array}{l}1 \\
3 \\
3\end{array}$ & $\begin{array}{l}\text { No effect } \\
\text { Facilitation } \\
\text { No effect }\end{array}$ \\
\hline
\end{tabular}

Note: PRP, proportion of related trials (in \%); ISI, inter-stimulus interval (in ms, except for the Monsell \& hirsh (1998) study); overlap, in number of shared phonemes; LDT, lexical decision task

${ }^{1}$ : Only the experiment that included a control condition was considered.

2: Because repetition trials were thought to encourage strategic processes, only the experiment that did not include them was considered. 